IZA DP No. 5193

Understanding Neighbourhood Effects: Selection Bias and Residential Mobility

Lina Bergström

Maarten van Ham

September 2010 


\title{
Understanding Neighbourhood Effects: Selection Bias and Residential Mobility
}

\author{
Lina Bergström \\ Uppsala University
}

Maarten van Ham

University of St Andrews

and IZA

\section{Discussion Paper No. 5193 \\ September 2010}

\author{
IZA \\ P.O. Box 7240 \\ 53072 Bonn \\ Germany \\ Phone: +49-228-3894-0 \\ Fax: +49-228-3894-180 \\ E-mail: iza@iza.org
}

\begin{abstract}
Any opinions expressed here are those of the author(s) and not those of IZA. Research published in this series may include views on policy, but the institute itself takes no institutional policy positions.

The Institute for the Study of Labor (IZA) in Bonn is a local and virtual international research center and a place of communication between science, politics and business. IZA is an independent nonprofit organization supported by Deutsche Post Foundation. The center is associated with the University of Bonn and offers a stimulating research environment through its international network, workshops and conferences, data service, project support, research visits and doctoral program. IZA engages in (i) original and internationally competitive research in all fields of labor economics, (ii) development of policy concepts, and (iii) dissemination of research results and concepts to the interested public.
\end{abstract}

IZA Discussion Papers often represent preliminary work and are circulated to encourage discussion. Citation of such a paper should account for its provisional character. A revised version may be available directly from the author. 
IZA Discussion Paper No. 5193

September 2010

\section{ABSTRACT \\ Understanding Neighbourhood Effects: Selection Bias and Residential Mobility}

The number of studies investigating neighbourhood effects has increased rapidly over the last two decades. Although many of these studies claim to have found evidence for neighbourhood effects, most 'evidence' is likely the result of reversed causality. The main challenge in modelling neighbourhood effects is the (econometric) identification of causal effects. The most severe problem is selection bias as a result of selective sorting into neighbourhoods. This paper argues that in order to further our understanding of neighbourhood effects we should explicitly incorporate neighbourhood sorting into our models. Neighbourhood effect studies are in the situation where the processes behind one of its key methodological problems (selection bias) are also critical to fully understand the neighbourhood context itself. It is thus remarkable that residential mobility and neighbourhood sorting has been almost completely ignored in the neighbourhood effects literature.

JEL Classification: $\quad$ I30, J60, R23

Keywords: neighbourhoods, selective mobility, neighbourhood effects, selection bias, migration, residential mobility

Corresponding author:

Lina Bergström

Institute for Housing and Urban Research

Uppsala University Box 785

SE-801 29 Gävle

Sweden

E-mail: lina.bergstrom@ibf.uu.se

\footnotetext{
* Chapter prepared for the forthcoming book Neighbourhood Effects Research: New Perspectives, edited by Van Ham M., Manley D., Bailey N., Simpson L., Maclennan D (Chapter 4). Springer Dordrecht (http://www.springer.com/).
} 


\section{Introduction}

The number of studies investigating neighbourhood effects has increased rapidly over the last two decades. Although many of these studies claim to have found evidence for neighbourhood effects, most 'evidence' is likely the result of reversed causality. The main challenge in modelling neighbourhood effects is the (econometric) identification of causal effects. The most severe problem is selection bias as a result of selective sorting into neighbourhoods (Jencks \& Mayer, 1990; Tienda, 1991; Duncan et al., 1997; Galster, 2008; Bergström, forthcoming). Selection bias occurs when the selection mechanism into neighbourhoods is not independent from the outcome studied. For example, unemployed people are more likely to move into deprived neighbourhoods than employed people. If this selection mechanism is not adequately controlled for in modelling the effect of living in a deprived neighbourhood on unemployment, a correlation between unemployment and neighbourhood deprivation might be mistaken for a neighbourhood effect.

The selection bias problem is well-known and many recent studies on neighbourhood effects attempt to correct for it in one way or another, often using econometric modelling techniques. This paper argues that selection bias in neighbourhood effects research is more than a statistical error and that understanding selection into and out of neighbourhoods is at the heart of understanding neighbourhood effects. Neighbourhood selection is the result of residential mobility choices made by households within a restricted choice set (van Ham \& Feijten, 2008; Feijten \& van Ham, 2009; van Ham \& Clark, 2009). These residential choices sort households with different characteristics into different (types of) neighbourhoods, producing and affecting patterns of residential segregation. The sorting process can either reproduce or alter neighbourhood characteristics over time. Especially neighbourhoods with high levels of population turnover may experience high levels of change within relatively short time frames.

If we are to understand mechanisms behind neighbourhood effects, more knowledge is needed about residential mobility and the selective sorting into and out of neighbourhoods (see also Bergström, forthcoming). Residential mobility should be an integral part of the conceptual framework which we use to understand neighbourhood effects. This paper will empirically and conceptually illustrate the connections between the problem of selection bias and selective mobility patterns and processes. We will argue that a better understanding of mobility and neighbourhood sorting is key in understanding neighbourhood effects and that processes of selective mobility should be incorporated into models of neighbourhood effects. The remainder of this paper is organised as follows. First, we will illustrate the importance of selective mobility using data for three neighbourhoods in Stockholm, Sweden. Second, we will discuss theories of residential mobility and the results of existing empirical studies. Third, we present an approach to incorporate residential mobility in models of neighbourhood effects. The final section offers a conclusion and discussion.

\section{An empirical illustration of selective mobility patterns}

There are several ways in which patterns of residential mobility can be described as 'selective'. One is that some groups are more mobile than others. Especially young adults tend to be very mobile. According to Andersson (2000), half of the moves the 
average Swede makes during his or her life time (about ten) take place between the ages of 18 and 34. Other features associated with mobility are household composition (single households move relatively often) and housing tenure (renters move more often than homeowners). In the context of understanding neighbourhood effects, we are not so much interested in the differences between groups in mobility rates, but more in mobility patterns and their causes: who moves to (or stays in) certain types of neighbourhoods and why?

The sorting of people with different characteristics into and out of different types of neighbourhoods is one of the main causes of residential segregation. Selective mobility can cause the neighbourhood population composition to change dramatically within a relatively short period of time. This has been illustrated by studies of white flight in the US (see Ellen, 2000). Ethnic segregation is partly caused by the "flight" of white people from neighbourhoods where the share of black inhabitants has reached a critical point. The overrepresentation of whites among outmovers makes the neighbourhood turn even more "black", resulting in the continued and accelerated out-mobility of white inhabitants. It is more common however, that selective mobility patterns reproduce existing neighbourhood characteristics. For example, neighbourhoods with high concentrations of immigrants often attract new immigrants. This mechanism can partly be explained through residential preferences (they want to live in these neighbourhoods because of, for example, ethnic specific services), and partly through restrictions within the local housing markets (the ethnic concentration neighbourhoods are relatively affordable and thus available for lowincome groups). The relative weight of these two explanations will differ between (ethnic and socio-economic) groups and between housing markets.

This section of the paper provides some empirical examples of selective mobility patterns and their relations to neighbourhood change or reproduction. We present moving patterns and neighbourhood trends for the 1990 to 2008 period for three neighbourhoods in Stockholm, Sweden. These neighbourhoods are by no means representative for the city as a whole but they are chosen because of their different characteristics and mobility patterns. The three neighbourhoods are Bjursätra, located in the south of Stockholm and part of the relatively deprived larger area of Rågsved; Ängbylunden, which is a villa neighbourhood known for its green spaces, is located in the west of Stockholm and part of the larger area Bromma; and Rinkeby, one of Sweden's best-known deprived and ethnically segregated neighbourhoods located in the North West of Stockholm. The data used for this study is derived from the GeoSweden database, which is a longitudinal micro-database of the entire Swedish population drawn from a number of different administrative registers. This data is unique, as it consists of linked annual demographic, geographic and socio-economic data for each individual living in Sweden, for the whole 1990 to 2008 period. With the data it is possible to follow people over the full 18 year period and to study their residential histories, including their neighbourhood histories.

Figures 1 and 2 show the share of foreign born people and the share of employed people (aged 20-64) in the three neighbourhoods for the 18 year period, and the averages across all neighbourhoods in Stockholm municipality. The data clearly illustrates how some neighbourhoods can change dramatically over time. The data shows that there are substantial differences in the share of foreign born inhabitants among the three neighbourhoods, from 7 \% in Ängbylunden in 2008 to $61.7 \%$ in Rinkeby. Over the 18 year period, the share of foreign born inhabitants has increased in the municipality as a whole and in two of the three neighbourhoods; Rinkeby and Bjursätra. The increase in Rinkeby is fairly modest, 5.7 percentage points, while 
Bjursätra has witnessed a dramatic increase of foreign born people: over the 18 years, the share of foreign born in the neighbourhood has more than doubled, from $20.1 \%$ in 1990 to a level where almost half the population was born in another country. In Ängbylunden, the share of foreign born has actually declined over the period.

Figure 2 shows that employment levels have increased in Stockholm municipality since 1994 (due to a change in the measurement of employment in 1993, data for that year and earlier was left out the figure). Employment levels were relatively low in the early 1990s because of the economic recession in Sweden. However, while the municipal average signals a substantial increase in employment levels, the trends in Bjursätra and Ängbylunden are quite stable, albeit at different levels. While Ängbylunden had an employment rate of $86.3 \%$ in 2008, the equivalent for Bjursätra was $62.0 \%$. Rinkeby is the only one of the three neighbourhoods that experienced an increase in employment levels similar to the average, but the neighbourhood remains at a level well below the municipal average. In 2008, the employment level in Rinkeby was 45.3 \% (Stockholm average $78.7 \%$ ). The ranking of the three neighbourhoods remain the same over the 18 years: Ängbylunden is the neighbourhood with the highest employment levels and Rinkeby is the neighbourhood with the lowest employment levels. In other words, employment patterns in these three neighbourhoods are reproduced during the period. This is important in the context of understanding neighbourhood effects: these neighbourhoods most likely receive people with employment characteristics similar to those who are already living there.

Figure 1. Share of foreign born residents, 1990-2008.

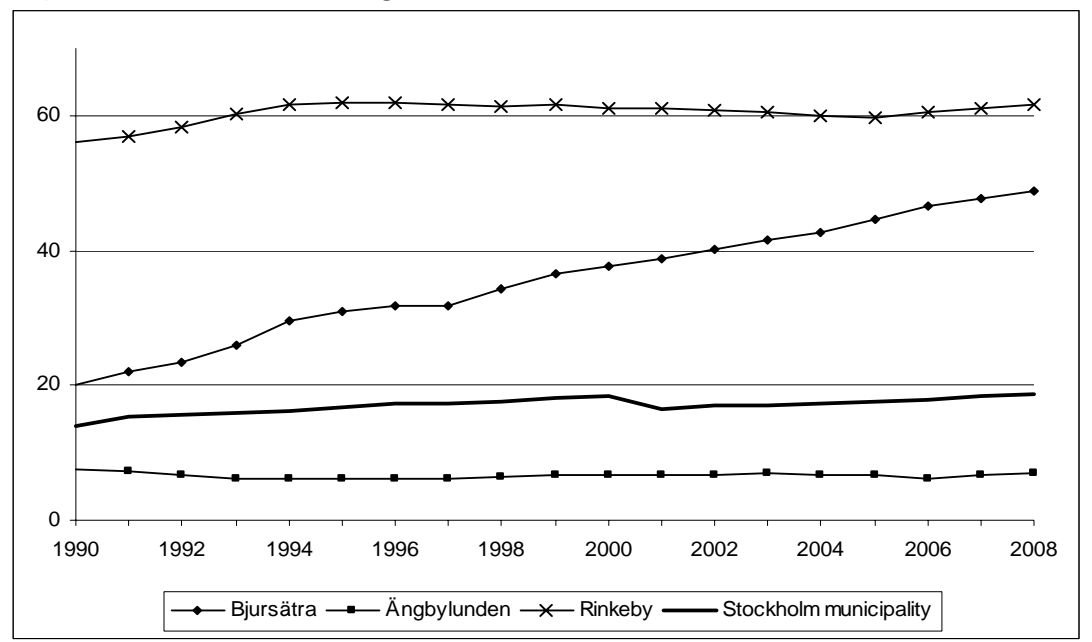

Source: Author's calculations using data from GeoSweden.

There are several mechanisms which can explain the patterns in the share of ethnic minorities and employment levels in these three neighbourhoods. For example, the share of ethnic minorities in a neighbourhood could change because of demographic events (see Finney \& Simpson, 2009) but also due to selective mobility of the majority and minority population. Similarly, changes in the employment rates in a neighbourhood could be explained by labour mobility (in and out of employment) of neighbourhood residents, but also by selective mobility of employed and unemployed residents into and out of neighbourhoods. If employment rates in a neighbourhood stay relatively low over a longer period of time, such as is the case in Rinkeby, this 
might be caused by in-mobility of people with similar employment characteristics as the neighbourhood population.

Figure 2. Share of employed residents (aged 20-64), 1994-2008.

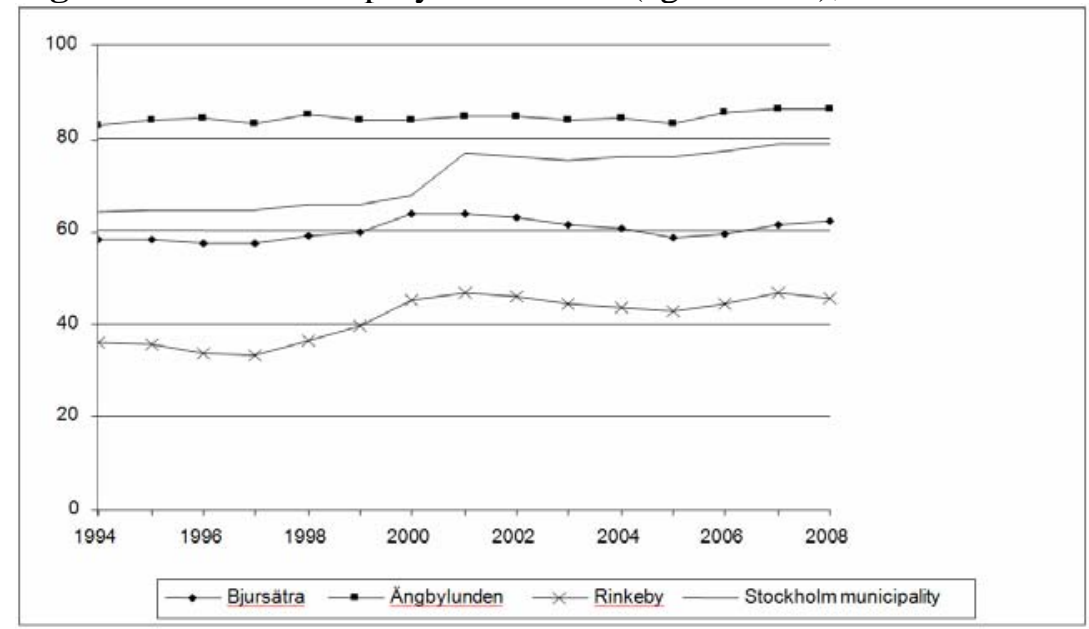

Source: Author's calculations using data from GeoSweden.

Table 1 shows population turnover rates for the three neighbourhoods, based on the number of people leaving the neighbourhood. A move is defined as a change of neighbourhood between two years, so within-neighbourhood mobility is not included in the figures. Table 1 shows us that population turnover rates are fairly similar (between 8 and 13\%) in the three areas, despite their very different characteristics, and turnover rates are very stable over time. Ängbylunden, which was the villa neighbourhood, has the lowest level of population turnover with $8 \%$ a year. All three neighbourhoods experienced an increase in population over the 18 year period, which suggests that the out-movers were replaced by in-movers. Differences in characteristics between out-movers and in-movers, and natural change of the neighbourhood population are responsible for changes in the population composition of the neighbourhoods.

Table 1. Number of inhabitants and turnover rates, 1990 and 2007/2008.

\begin{tabular}{|c|c|c|c|}
\hline \multirow[b]{2}{*}{ Number of Inhabitants } & Bjursätra & Ängbylunden & Rinkeby \\
\hline & & & \\
\hline 1990 & 9,022 & 4,505 & 13,222 \\
\hline 2008 & 10,576 & 5,227 & 14,996 \\
\hline \multicolumn{4}{|l|}{ Turnover rate $^{1}$} \\
\hline 1990 & 0.13 & 0.08 & 0.13 \\
\hline 2007 & 0.13 & 0.08 & 0.11 \\
\hline
\end{tabular}

${ }^{1}$ The turnover rate is based on the number of out-movers from the neighbourhood. 2007 is the last year for which a turnover rate can be calculated.

Source: Author's calculations using data from GeoSweden.

To better understand the changes in ethnic composition and employment levels (Figures 1 and 2) we show the shares of foreign born and employed people among inand out-movers to the three neighbourhoods during the same time period (Figure 3 and 4). Figure 3 clearly shows how the share of foreign born among in-movers in both Bjursätra and Rinkeby consistently exceeds the share of foreign born among out- 
movers. This produces the increase of immigrants in the two areas as observed in Figure 1. The stable ethnic composition of Ängbylunden is explained by similar shares of foreign born among in- and out-movers. We can also see that the most immigrant-dense area (Rinkeby) attract the highest share of immigrant in-movers while few move to Swedish majority neighbourhood of Ängbylunden. The share of immigrants moving to Bjursätra is constantly increasing during the period indicating a positive relationship between the share of immigrant in-movers and the share of foreign born in the neighbourhood.

Figure 3. Share of foreign born among in-movers and out-movers, 1991-2007.

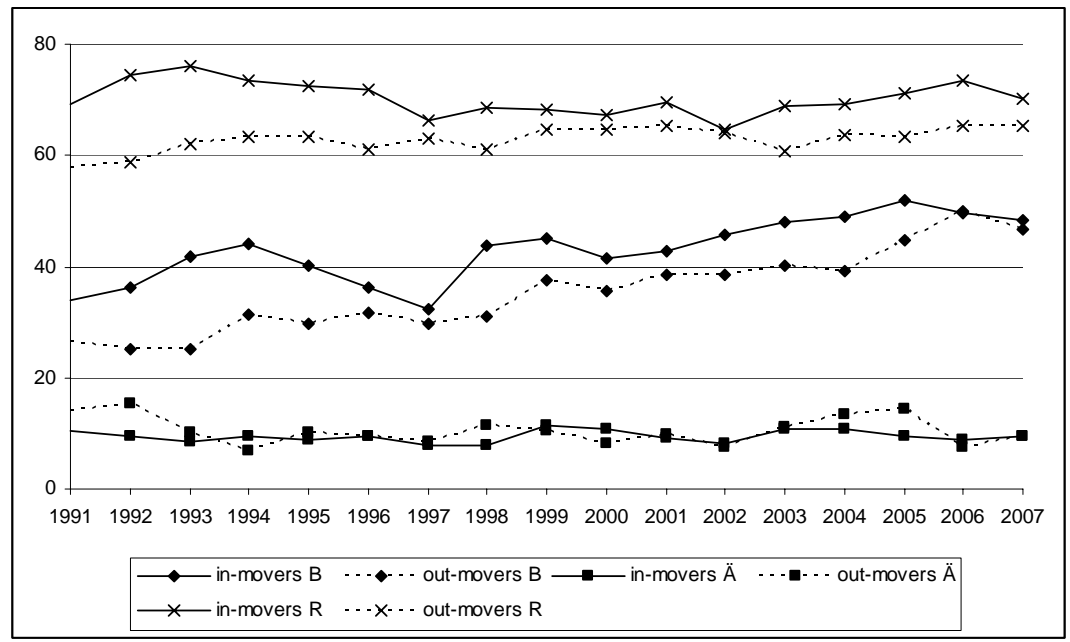

Source: Author’s calculations using data from GeoSweden.

Figure 4. Share employed (age 20-64) among in-movers and out-movers, 1994-2007.

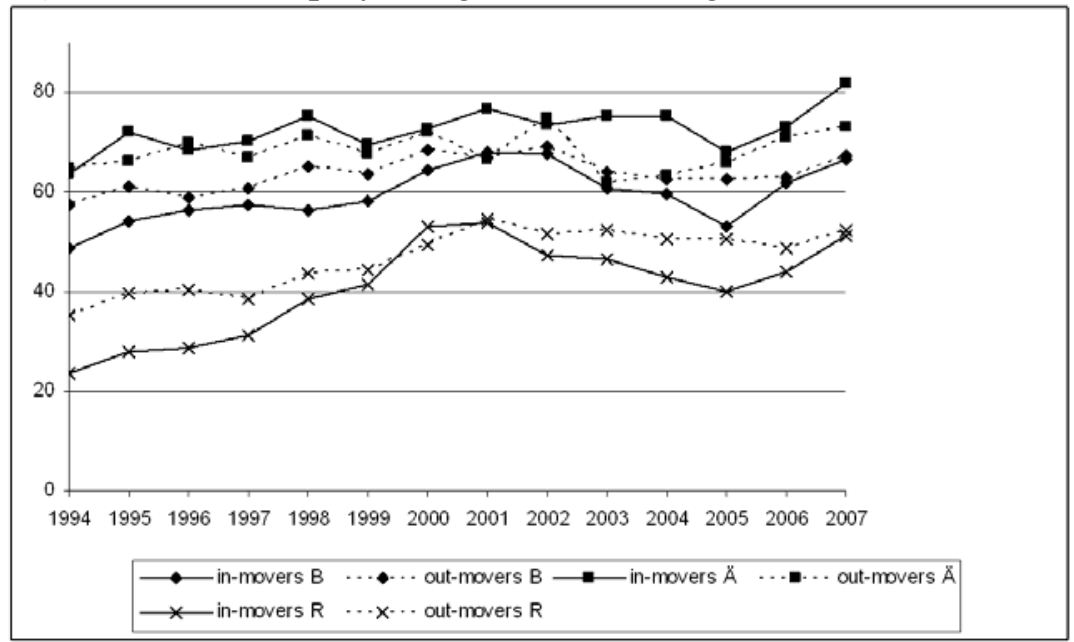

Source: Author’s calculations using data from GeoSweden.

Whereas Rinkeby and Bjursätra both had a positive "immigrant gap", both neighbourhoods experienced a negative employment gap; the share of employed people is higher among those leaving the respective neighbourhoods than among those moving to the neighbourhoods (Figure 4). Thus, the low levels of employment in especially Rinkeby are reproduced through selective moving patterns. This is an important observation as its shows that selective mobility is likely to explain (at least 
part of) the correlation between individual level unemployment and neighbourhood unemployment levels. There is also a very small employment gap between in-movers and out-movers in Ängbylunden, but going in the opposite direction. This is not surprising given that moving to Ängbylunden requires more financial resources than moving to any of the other two areas.

Figures 3 and 4 clearly illustrate how the characteristics of in- and out-movers can affect the neighbourhood population composition in terms of ethnic composition and employment levels. Selective mobility can result in either reproduction of existing characteristics, or in a change in characteristics over time. To further illustrate how individuals with different characteristics sort into different neighbourhoods, the characteristics of in-movers to each of the three neighbourhoods in 2008 are described in Table 2.

Table 2. Characteristics of in-movers, 2008.

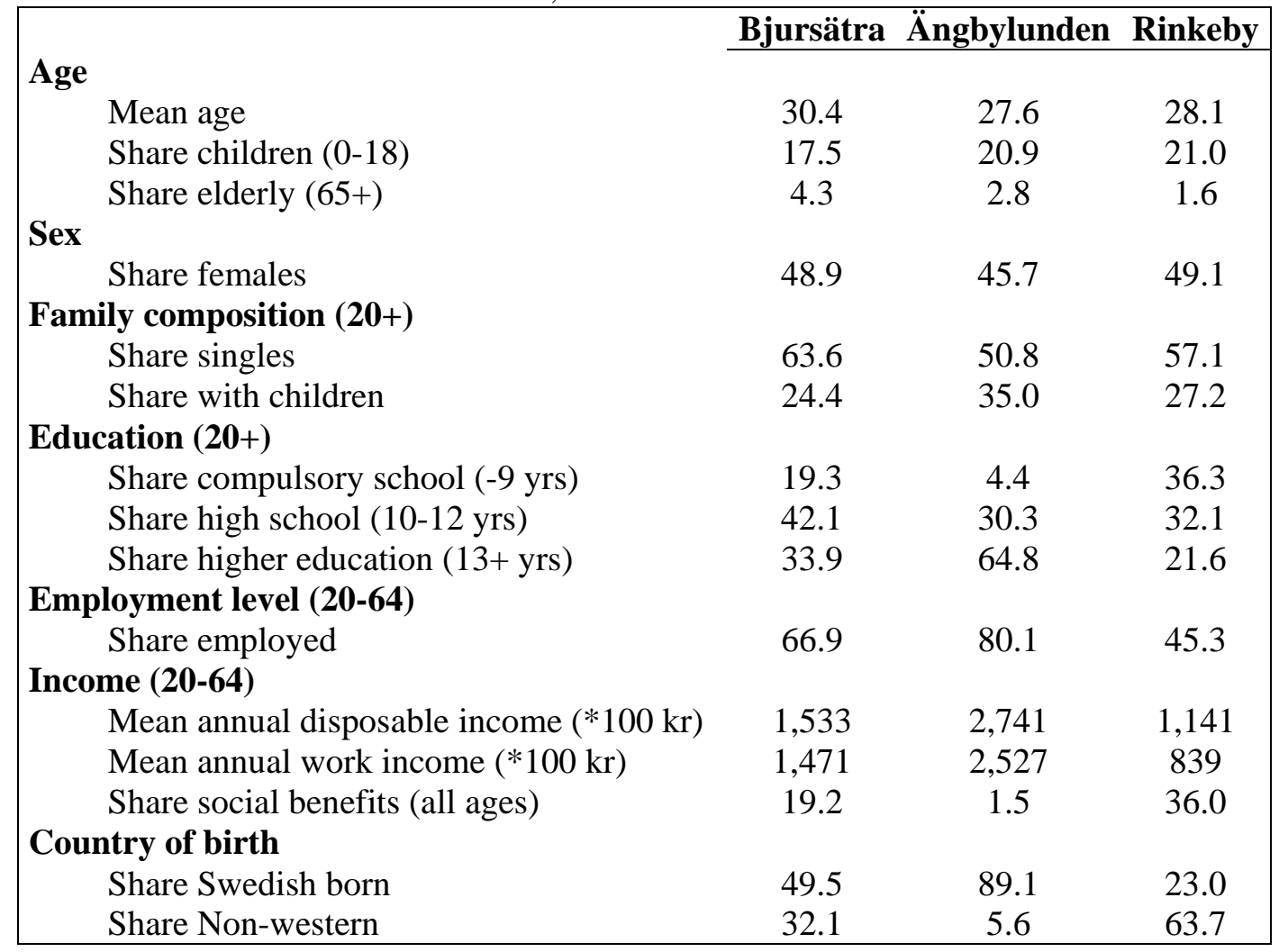

Source: Author's calculations using data from GeoSweden.

The Table shows no large differences in terms of age and gender composition but inmovers to Ängbylunden have a substantially stronger socio-economic position than in-movers to the other two neighbourhoods, and especially Rinkeby: they have higher levels of education, higher levels of employment, higher incomes, and are less dependent on social benefits. Thus, in accordance with many previous studies, the results show that individuals with stronger socio-economic positions move to more affluent neighbourhoods, while those with less resources move to more deprived areas. These mobility patterns reproduce the neighbourhoods' relative status and patterns of urban socio-economic segregation over time. A similar conclusion can be drawn for ethnic patterns, where nine out of ten in-movers to the Swedish majority 
neighbourhood Ängbylunden are Swedish born, while the respective figures for the more immigrant-dense areas of Bjursätra and Rinkeby are $49.5 \%$ and $23.0 \%$.

The above data analyses clearly show how mobility patterns are selective and how this selectivity reproduces or changes neighbourhood characteristics. Selective in-mobility of people into neighbourhoods is an issue that needs to be addressed in studies of neighbourhood effects. If in a neighbourhood with relatively low employment levels those who get a job leave the neighbourhood, and are replaced by others without a job, it is not the neighbourhood which causes unemployment, but the neighbourhood housing stock attracts unemployed people who cannot afford to live elsewhere. If the share of employed people among in-movers is much lower than among out-movers, this will seriously bias models of neighbourhood effects if not adequately controlled for.

Selective mobility and the resulting residential patterns would cause serious problems in neighbourhood effects studies if segregation was extreme, for example, when all low income residents live in the most deprived neighbourhoods. In such a case there would be no variation and therefore no control groups. Such extreme segregation would make it impossible to assess the effect of living in certain types of neighbourhoods. This is however rarely the case so at least in theory, selective mobility should not be a problem if we can adequately measure the selection mechanisms. Both the ethnicity and employment status, as used in the above examples, of in- and out-movers are easily measureable. However, selective mobility patterns become a problem if they are caused by unmeasured characteristics (characteristics not available in the data used) that are correlated with the outcomes of a neighbourhood effect study. Examples of such characteristics are soft skills, initiative, risk taking behaviour, which can all be expected to be also related to the probability to find and keep a job. To better understand how people decide whether to move or not and where to move to we must look into theories and studies of residential mobility.

\section{Selective mobility and the selection problem}

Understanding why people end up in certain types of neighbourhoods is complicated by the fact that housing is a composite good (see van Ham, forthcoming). A dwelling can be described by its various characteristics such as tenure, size, style, quality, and (relative) location. One cannot buy a single aspect of a dwelling separately as dwellings are bundles of characteristics, including the neighbourhood (van Ham, forthcoming). The type of housing available in certain neighbourhoods, in terms of tenure (rented or owner-occupied) and price is important in understanding how households sort over neighbourhoods. Some neighbourhoods will never be considered by some types of households because they are either beyond their financial means, or because they do not offer the right types of dwellings. It is important to be critical of the concept of choice here as most households choose their dwelling, and associated neighbourhood, within a very constrained choice set (van Ham, forthcoming a, b). In fact, some households have no choice at all, especially when they depend on housing offered by social landlords, which is often concentrated in a limited number of neighbourhoods within a city. Notwithstanding the above, it can be argued that selfselection also plays a role in the choice of neighbourhoods. Households also choose their neighbourhood based on the reputation of the place (Permentier et al., 2009), and 
based on other personal preferences. So both structural factors (the housing market) and individual preferences sort households into neighbourhoods.

Some of the factors which influence neighbourhood choice are easily observable using standard surveys. Others are more difficult to measure and are often not observed in the data (see earlier in this paper). In neighbourhood effects studies a problem arises when these unobserved characteristics also influence the individual outcome under study, which will lead to biased estimates. Several authors list selection bias as one of the most urgent issues to solve in the field of neighbourhood effects research (Jencks \& Mayer, 1990; Tienda, 1991; Duncan et al., 1997; Galster, 2008; van Ham \& Manley, 2010; Bergström, forthcoming). However, not everyone agrees on the direction of selection bias. Jencks and Mayer (1990) and Tienda (1991) argue that selection bias results in overestimated neighbourhood effects while BrooksGun et al. (1997) suggest that the opposite could also occur. This would, for example, be the case if those being the most negatively affected by a neighbourhood factor also are the first ones to leave. The extent of selection bias is also unclear. Some authors (e.g. Dawkins et al., 2005; Galster et al., 2007; Galster et al., 2008) find statistically significant evidence of neighbourhood effects even after controlling for selection. Others argue that their results indicate that selection explains all the correlation between neighbourhood characteristics and individual outcomes: with other words, what scholars believe to be a neighbourhood effect is nothing but a selection effect. For example, Oreopoulos (2003) found a positive correlation between living in wealthier areas or Toronto and income, employment and welfare participation, but only for those living in private housing. He found no such evidence for those living in social housing. He explained this by arguing that the housing allocation of those in social housing is more or less random (housing officers allocate housing based on need and waiting lists), while the choice of neighbourhood for those in private housing is strongly related to their socio-economic status. Oreopoulos (2003) concluded that he did not find evidence for causal neighbourhood effects. Van Ham and Manley (2010) found similar results using longitudinal data for Scotland. They only found correlations between neighbourhood characteristics and individual labour market outcomes for homeowners, but not for social renters. The results by Oreopoulos and van Ham and Manley do not show that neighbourhood effects do not exist, but they clearly show that selection effects are a significant problem when estimating neighbourhood effects.

The problem of selection effects is illustrated by Figure 5. A correlation between neighbourhood characteristics and an individual level outcome can either be the result of selective mobility, or of neighbourhood characteristics (see the chapter by Galster, 2011 for an extensive list of mechanisms through which the neighbourhood can affect individual level outcomes). To be able to draw the conclusion that the neighbourhood has a real causal effect on individual level outcomes, the selection effect has to be accounted for. Figure 5 also illustrates how mobility decisions of individuals and groups result in selective mobility patterns (the dashed arrows). Such mobility patterns do in turn affect the composition and characteristics of neighbourhoods and potentially also the entire urban neighbourhood hierarchy, as illustrated by our own empirical analysis earlier in this paper.

To understand why selection bias may occur, and to understand the possible extent and direction of bias, we must look into the issue of neighbourhood sorting; how and why do households sort themselves into different types of neighbourhoods. Although there is a very large literature on residential mobility choices in terms of the type and tenure of dwellings chosen, the literature studying neighbourhood choices is 
relatively small. One reason is that the most common framework for studying residential mobility treats housing choice as the result of interaction between household needs, demands and preferences and the characteristics of dwellings. Neighbourhood choice is in such a framework a by-product of the distribution of available and attractive dwellings. A relatively recent set of studies are however arguing that more attention must be directed to the role of the neighbourhood in the residential choice process (Lee et al., 1994; Kearns \& Parkes, 2003; Clark et al., 2006; Clark \& Ledwith, 2006; van Ham \& Feijten, 2008; Feijten \& van Ham, 2009; van Ham \& Clark, 2009). Two sets of (interrelated) literatures are of special relevance for understanding neighbourhood choice; the literature focusing on how residential mobility choices are made, and the literature focusing on understanding residential segregation and how it is maintained by selective mobility patterns.

Figure 5. An illustration of the relationship between selective mobility and the selection problem.

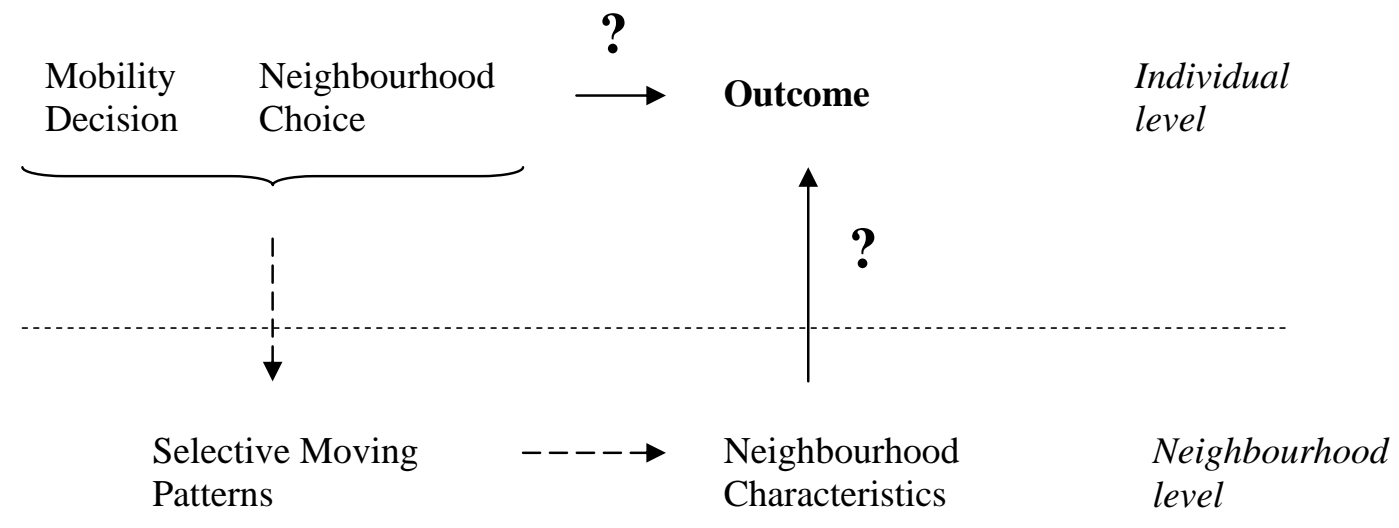

Factors affecting neighbourhood choice

In their now classical study on residential mobility, Brown and Moore (1970) divide the mobility decision into two separate choices: the decision to leave and the choice of destination. Both of these decisions are undertaken within a set of needs, preferences, and constraints. The choice of destination is often biased to certain areas. Brown and Moore use the concept of awareness space to refer to those places of which the household had knowledge of before the search process began. The search space, they argue, is often found within this awareness space; "[t]he household will search only those areas contained within its awareness space that satisfy the environmental and locational criteria of its aspirations, i.e., its search space” (Brown \& Moore, 1970, p.9). In other words, some areas are excluded from the search space. This exclusion, as well as the ultimate choice, is based on needs, preferences and constraints. Households preferring an owner-occupied detached dwelling will only search areas where such housing is available. Households which cannot afford to buy their own house will only search in neighbourhoods where rental dwellings are available. Furthermore, Brown's and Moore's argument claims that household will primarily search in neighbourhoods that are familiar to them, so information about alternatives plays an important role in the choice process (see also van Ham, forthcoming a, b).

Besides information, financial resources are another important factor determining the outcome of the residential choice process. The more one earns, the larger the choice set of dwellings and neighbourhoods. Banks and other mortgage 
lenders have a large influence on the resources available to households to buy property on the market. And, as discussed earlier, the structure of the local housing market has an important effect on the residential choice process. People can only move to neighbourhoods where there is vacant housing available. The constraints faced by some households are so severe that is misleading to talk about housing choice (van Ham, forthcoming a, b). For example, households in desperate and urgent need of housing are often forced to accept the first available option, often in less desirable neighbourhoods (van Ham \& Manley, 2009). Most cities are spatially (and socially) segregated along socio-economic lines, and the purchasing power of households is an important factor in neighbourhood sorting (Bergström et al., 2010). The most attractive and expensive areas are inaccessible for a large share of the population. Several studies have shown how people leave the most distressed areas as their incomes increase, leaving vacancies that are filled by those whose options are very limited (e.g. Skifter Andersen, 2003; Andersson \& Bråmå, 2004; Sampson \& Sharkey, 2008).

However, although some households face severe constraints on the housing market, most households have some degree of choice. A household's choice set may be constrained to cheep dwellings in less attractive areas but if there are vacancies in a variety of neighbourhoods, households can still choose the alternative which best matches their specific (locational) needs and preferences, even if none of the alternatives is considered very good. Many factors have been suggested to affect the choice of destination (and also the decision to move). Brown's and Moore's (1970) review list five categories: accessibility (to city centre, communications, service, green areas etc.), physical characteristics of the neighbourhood (physical condition of street and sidewalk, layout, beauty), services and facilities (quality and accessibility), social environment (socio-economic, ethnic, and demographic composition, friends and friendliness), and individual site and dwelling characteristics (costs, housing size etc.). Obviously, households differ in terms of which aspects they find most important and how they value these aspects, and their attitudes and preferences change over time. In general, families with children tend to value child friendliness and access to good quality schools while young singles often move toward the city centres.

In a recent survey ${ }^{1}$ (spring 2009) among a sample of "movers" and "stayers"2 in four neighbourhoods in Uppsala, Sweden, respondents in the age group 28-55 were asked how important certain neighbourhood features were to them when thinking of potential destinations. Those that seemed most important to the respondents were neighbourhood safety, cleanness, aesthetic beauty, access to green spaces, quiet neighbours, and a more general provision of services such as grocery stores and public transport (see Figure 6). Previous studies support these results as they have found neighbourhood satisfaction and attachment to be correlated with physical conditions and appearance, quality and amount of services, safety, and stigmatization

\footnotetext{
1 The survey is part of the project "Den etniska segmenteringens mekanismer - exemplet bostadsmarknaden" [Ethnic housing segmentation and discrimination - a study of institutional practices and preferences], sponsored by the Swedish Council for Working Life and Social Research, and conducted by Roger Andersson, Irene Molina, and Lina Bergström at the Institute for Housing and Urban Reseach, Uppsala University, and by Åsa Bråmå at the Centre for Municipality Studies, Linköping University.

2 All respondents had stayed two years (2005-2007) in one of the four selected neighbourhoods (Luthagen, Svartbäcken/Tunabackar, Stenhagen, Gottsunda). About 50 \% (where possible, otherwise the entire moving population) had moved to a different neighbourhood in 2008 while the other 50\% remained in the same neighbourhood. The total number of respondents was 1,257 , the response rate was $48.2 \%$.
} 
(Burrows \& Rhodes, 2000; Parkes et al., 2002; Kearns \& Parkes, 2003; Permentier et al., 2009). Some minor differences were found among the different age categories, where the youngest age groups (aged 28-35) placed more importance on good access to schools and their working places where the older respondents (aged 45-55) found access to green areas and neighbourhood cleanness to be more important. Families with children found neighbourhood reputation, neighbourhood safety, and child friendliness, and access to schools, sports facilities and parking lots more important than singles, who in turn favoured access to restaurants and cafés and public communications more than did the families. However, all categories found the same factors (the above mentioned) to be the most important ones.

Figure 6. Share of respondents ranking different neighbourhood factors to be “important” or "very important” (4 or 5 on scale 1-5).

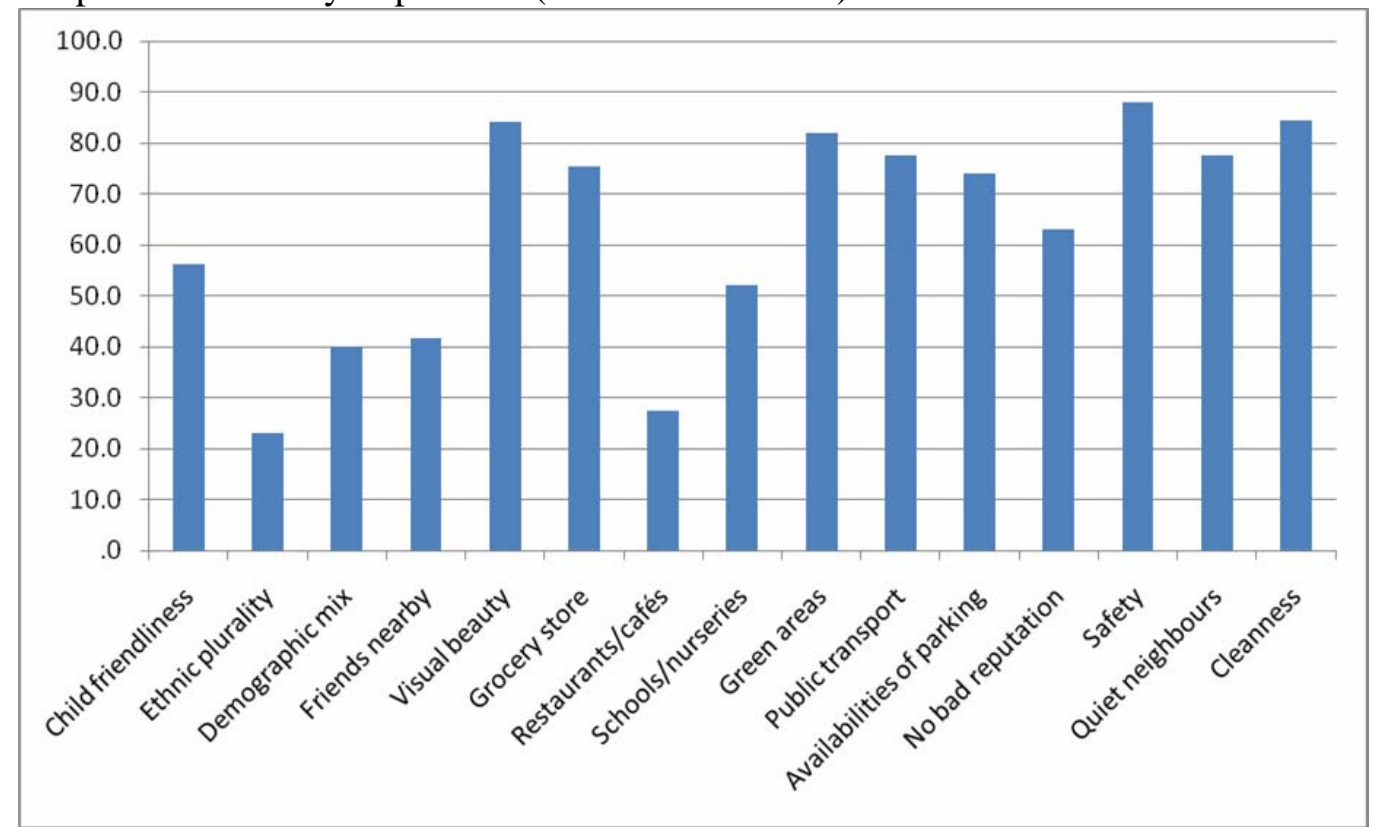

Source: Own survey, all respondents, ages 28-55.

No major differences regarding the most important neighbourhood characteristics were found between the "mover" and "stayer" categories in the survey. Other studies have shown that neighbourhood satisfaction and neighbourhood attachment are correlated with moves and moving intentions where those who are the most satisfied are the least likely to (want to) leave (Galster, 1987; Lee et al., 1994; Clark \& Ledwith, 2006; Guest et al., 2006; van Ham \& Feijten, 2008; Feijten \& van Ham, 2009; Permentier et al., 2009). The previous discussion indicates that those living in safe, clean, quiet neighbourhoods with good access to services and a good reputation are the least likely to have a desire to leave. Distressed neighbourhoods are the least likely to have all these attributes and they do tend to have the highest turnover rates, although it is unclear whether this is due to neighbourhood characteristics or population composition (see e.g. Bailey \& Livingston, 2007; van Ham \& Clark, 2009). Moving plans are also affected by neighbourhood change, where households experiencing change, or believing that their neighbourhood will turn "worse" (in their opinion) will be more likely to express a wish to leave (Galster, 1987; Lee et al., 1994; Kearns \& Parkes, 2003; van Ham \& Feijten, 2008; Feijten \& van Ham, 2009; van Ham \& Clark, 2009). The survey did not find any large differences in 
neighbourhood characteristics found important among inhabitants of different neighbourhoods, with the exception of how respondents valued neighbourhood population diversity. The inhabitants of the most immigrant-dense neighbourhood expressed stronger preferences for both ethnic and demographic diversity compared to the residents of other neighbourhoods. These preferences were also stronger among "stayers" compared to those who had left the area.

The role of ethnic preferences (among both majority and minority groups) in relation to ethnic residential segregation has been a topic that has received much attention since the publication of Schelling's (1969; 1971) seminal papers in which he demonstrated that small differences in preferences between two groups could cause high levels of segregation due to adjusted, ethnically selective mobility patterns. Schelling's hypothesis was confirmed by Clark (1991) who even argued that the differences in preferences of ethnic composition between whites and blacks were much larger than those hypothesized by Schelling and that especially white people expressed strong preferences for ethnic homogeneity in the neighbourhoods (see also Clark, 1992). Ethnic preferences (of the majority population) are an important explanation for the ethnically selective mobility patterns creating ethnic residential segregation as demonstrated by the white flight/white avoidance theories. White flight theory suggest that the white/native population leaves neighbourhoods when the share of minorities becomes too high; white avoidance theories hypothesise that when whites choose a neighbourhood they avoid areas with high shares of minority inhabitants (Ellen, 2000). The theories have found empirical support in both the U.S. (e.g. Crowder, 2000; Quillian, 2002) and in European countries. For example, van Ham \& Feijten (2008), Feijten and van Ham (2009), and van Ham and Clark (2009) have found for the Netherlands that native Dutch people express stronger wishes to leave when the percentage of ethnic minorities in their neighbourhood increases, and Bråmå (2006) shows that native Swedes tend to avoid immigrant-dense neighbourhoods.

The Schelling argument emphasizes within-group preferences with regard to living among similar others, whereas the white flight/avoidance theories also touch upon attitudes towards other groups. Several scholars have tried to explain the aversion of especially whites (or natives) towards living in ethnically mixed neighbourhoods. Some studies suggest that race $^{3}$ is an independent factor, and thus that racism (of especially whites) is an important variable explaining ethnic segregation (e.g. Zubrinsky \& Bobo, 1996; Emerson et al., 2001). Other studies argue that it is not race per se that make whites less willing to move into black neighbourhoods but that race is a proxy for other attributes, such as housing prices, crime levels or general neighbourhood standards (e.g. Clark, 1992; Harris, 1999; Crowder, 2000). Ethnic minorities are more likely to be poor, and are therefore also more likely to live in poverty areas. So according to the race-proxy argument, whites do not avoid ethnic minority areas, but they avoid poor neighbourhoods which are often also ethnic minority areas. The spatial assimilation model argues that ethnic segregation is the outcome of differences in socio-economic resources together with a lack of cultural assimilation of minorities. According to the theory, the residential mobility patterns of ethnic minorities will become increasingly similar to those of the majority population as they become more integrated and their socio-economic position becomes stronger. A complementary theory is the place stratification model,

\footnotetext{
${ }^{3}$ The U.S. literature consistently refers to "race” while the European literature refers to "ethnicity” and "immigrant status”.
} 
which emphasises the importance of other forms of constraints than economical and cultural ones. It argues that, for example, discrimination and housing availability or housing allocation rules restrict the opportunities for ethnic minorities to have housing careers similar to natives and that these differences will remain even after immigrants have become more integrated (see Bolt \& van Kempen 2003 for an overview of the place stratification and spatial assimilation models). Studies have found evidence of housing market discrimination for several countries (for the U.S. see Turner et al., 2002).

An alternative theory argues that ethnic segregation is the result of the voluntary clustering of ethnic minorities. This literature emphasises how minorities can gain benefits from living together, such as keeping their own language and culture, having access to ethnic specific services such as specialised stores or places of worship, and having access to a local economic system. It has also been suggested that ethnic clustering is used as a means of defence against a hostile host society, but also that ethnic clustering might help to integrate into the host society (see for example Portes \& Manning, 1986). Bowes et al. (1997) have found that the Pakistani population in Scotland accepted to live in a deprived neighbourhood if that would make them live with more co-ethnics. Theories of voluntary clustering rely on relatively homogeneous ethnic concentration neighbourhoods. In Sweden (and many other parts of Europe) such neighbourhoods do not exist; some immigrant-dense neighbourhoods in Sweden contain between 50 and 100 different nationalities, making theories of voluntary clustering less applicable. Molina's (1997) study found that ethnic minorities living in an immigrant-dense area in Uppsala, Sweden, had the same housing and neighbourhood ambitions as the native population but were less able to realize them, thus pointing at different forms of constraints.

The above literature review suggest that the selective in- and out-mobility patterns found for Bjursätra, Ängbylunden and Rinkeby are most likely the result of a complex mixture of constraints of various forms and preferences for different types of dwellings and neighbourhoods. Existing studies provide knowledge of how different dwelling characteristics are related to mobility but we know less about how factors at the neighbourhood level affect neighbourhood choice and sorting. We know that some groups are more likely to move to, for example, ethnic concentration neighbourhoods than others but there is less knowledge on how households value ethnic composition in relation to, for example, socio-economic status of neighbours, neighbourhood safety, or reputation. There is also a need of research looking at how households choose between neighbourhoods: why does a household choose one "safe" neighbourhood over another, and how do households with very restricted choice sets rank neighbourhoods and dwellings available to them?

To further explore the neighbourhood dimension in mobility processes is not only an important task for the residential mobility literature but also something that would be of great importance for studies on neighbourhood effects. Such studies would provide us with a better knowledge of neighbourhood sorting processes and thus the problem of potential selection bias. It would make it possible to better incorporate sorting into models and measurements of neighbourhood effects.

\section{Methods for dealing with neighbourhood sorting and selection bias}

In this section of the paper, we argue that studies on neighbourhood choice and neighbourhood sorting would benefit from using alternative modelling strategies. We 
also discuss how these strategies can be incorporated into models of neighbourhood effects to control for the bias caused by selective mobility to neighbourhoods.

Most quantitative studies of neighbourhood sorting use logistic regression models, binary or multinomial, to model the probability that households move to a certain type of neighbourhood. These models treat neighbourhood choice as a function of the characteristics of individuals or households: for example, the models estimate how different individual characteristics, such as income, employment status or ethnicity, affect the likelihood of moving to neighbourhoods in category A relative to those in category B. Binary logistic regression models are by definition restricted to using only two outcome categories (for example whether or not a neighbourhood is deprived or ethnically concentrated). Multinomial logistic regression models can handle more alternatives but these become impractical to work with if the number is too large. The need to reduce the number of alternatives means that neighbourhoods need to be categorized based on, for example, poverty levels, levels of ethnic concentrations, housing tenure, or combinations of these. The models are of limited use to understand neighbourhood choice because they can only take a limited number of neighbourhood characteristics into account and neighbourhoods typically need to be grouped using a simple categorisation. In other words, studies using binary or multinomial logistic regression models teach us a lot about simple processes of neighbourhood sorting (where do people go) but little about how different neighbourhood factors affect the sorting process.

A type of model that can include multiple neighbourhood characteristics simultaneously is the conditional logit model ${ }^{4}$, introduced in the context of social sciences and residential mobility by McFadden in 1974. The conditional logit (or nested logit, introducing more neighbourhood dimensions) treats choice as a function of the characteristics of the alternatives within a choice set. In a residential mobility setting, this means that each individual can choose from a number of neighbourhood alternatives based on a large range of characteristics of these neighbourhoods. In a recent paper Bergström et al. (2010) modelled neighbourhood choice where each moving household was assumed to choose between 10 alternative neighbourhoods. Their model estimated the probability that households choose their actual destination (the other nine are random alternative neighbourhoods) based on neighbourhood characteristics such as the share of foreign born, the share of public renters and the median neighbourhood income. A weakness of the conditional logit model is that it cannot include individual characteristics directly because these do not vary within choice sets of neighbourhoods (only the characteristics of the neighbourhoods within a choice set vary, not the characteristics of the households making the choice). Individual characteristics can only be included when interacted with neighbourhood characteristics. The conditional logit model is well known in, for example, the transport choice literature, but is rarely used to estimate neighbourhood choice. To our knowledge, only three (very recent) studies have used it to estimate neighbourhood choice: Ioannides and Zabel's (2008) study on neighbourhood effects on housing structure demand; Quillian and Bruch's (2010) study modelling neighbourhood choice in relation to race and class; and Bergström et al. (2010) estimating neighbourhood sorting in Sweden.

We have so far in this paper argued that neighbourhood sorting processes are a major source of selection bias in studies of neighbourhood effects and that more

\footnotetext{
${ }^{4}$ For formal descriptions of the conditional logit model and how it differs from the multinomial logistic model, see McFadden (1974), Hoffman and Duncan (1988).
} 
knowledge is needed on these processes to fully understand the selection problem (see also Sampson \& Sharkey 2008). Most neighbourhood effect studies do still not adequately take neighbourhood sorting into account but an increasing number of studies attempt to address the issue. Oreopoulos (2003) and van Ham and Manley (2010) both argued that selection bias in models of neighbourhood effects is only a problem for those groups who have some degree of choice over where they live. Both studies found no neighbourhood effects for those in (to some extend randomly allocated) social housing, but did find 'effects' for those in private housing. They concluded that these 'effects' are most likely the result of reversed causation. By comparing those in private housing and those in social housing, Oreopolous and van Ham and Manley simulated an experimental setting. The best known examples of quasi-experiments are Chicago's Gatreaux assisted housing program and the American Moving to Opportunity (MTO) program. These programs allocated households to dwellings and neighbourhoods more or less randomly, thereby attempting to overcome selection bias. Although these studies are seen as the goldstandard in neighbourhood effects research, it has been argued they still suffer from selection bias as allocation to neighbourhoods was not 100 percent random.

For most studies it is not possible to execute large random trials and these studies often depend on register or survey data. A number of approaches can be used to limit the effects of selection bias when using such data. One approach is the use of sibling data to control for unmeasured parental characteristics by measuring differences in outcomes if the siblings have experienced different neighbourhood environments during their life-time (e.g. Aaronson, 1998). Instrumental variable approaches are also used to control for selection bias, which requires instruments to replace the variable that is correlated with the outcome of interest ( Galster et al., 2007). Difference models are also popular as they eliminate all time-invariant unobservable individual characteristics (see Galster et al., 2008). All these techniques theoretically remove bias, at least to some extent. However, unfortunately, they do not address the issue of selective mobility.

A classic technique to take selection mechanisms into account is the Heckman (1979) two-step model. It involves a first step in which the probability of sorting into a group is estimated, and a second step in which the outcome of interest is estimated for the specific group, thereby correcting for potential bias caused by the selection mechanism (see Heckman 1979). In the setting of a neighbourhood effect study, step one could be to model the probability of living in a certain neighbourhood and step two could be a model of neighbourhood effects. Although the two-step model has some disadvantages and has been criticized in the econometric literature (e.g. Puhani, 2000), it has the enormous benefit of including real measures of selective mobility and neighbourhood sorting. To our knowledge, only one study has attempted a twostep technique to account for bias in modelling neighbourhood effects: Ioannides and Zabel's 2008 paper in which they estimate how the neighbourhood context affects housing demand. The paper is very technical, but uses a promising advanced method to estimate neighbourhood sorting and to control for bias. The approach not only tackles the urgent problem of selection bias in the neighbourhood effect literature but also gives insight into neighbourhood sorting. It is thus a technique that benefits two literatures separately while also incorporating them methodologically into a holistic framework that increases our general understanding of neighbourhoods and residential segregation. 


\section{Concluding remarks}

This paper has argued that in order to further our understanding of neighbourhood effects we should incorporate neighbourhood sorting into our models. Many approaches to deal with selection bias treat neighbourhood sorting as a statistical nuisance. These approaches might do the job, but reveal nothing about the processes behind the potential bias. Neighbourhood sorting is of interest in its own right and surprisingly few studies focus on why certain households 'choose' certain neighbourhoods. An understanding of neighbourhood sorting is also key in understanding residential segregation and the production and reproduction of neighbourhoods of different characteristics and status. In other words, an understanding of neighbourhood sorting is important to understand the dynamic contexts (neighbourhoods) that neighbourhood effects theory assumes affect inhabitants.

Neighbourhood effect studies are thus in the situation where the processes behind one of its key methodological problems (selection bias) are also critical to fully understand the neighbourhood context itself. It is thus remarkable that residential mobility and neighbourhood sorting has been almost completely ignored in neighbourhood effects research. This paper has demonstrated how selective mobility patterns affect the neighbourhood context and have the potential to cause selection bias when modelling neighbourhood effects. In line with previous studies, we recognize the need for more studies focusing on neighbourhood sorting, especially how neighbourhood factors influence mobility decisions. Furthermore, most studies looking at neighbourhood choice focus on a range of general neighbourhood characteristics, such as employment rates and the percentage of ethnic minorities. More research is needed on the factors that cause households to choose, for example, one deprived neighbourhood over another. This point is important as some theories assume that processes and transmission mechanisms behind neighbourhood effects are neighbourhood-specific.

\section{References}

Aaronson, D. (1998) Using sibling data to estimate the impact of neighborhoods on children's educational outcomes, Journal of Human Resources 33 pp. 915-946.

Andersson, R. (2000) Varför flyttar man?, Hemort Sverige, Norrköping: Board of Integration, pp. 50-65.

Andersson, R. \& Bråmå, Å (2004) Selective Migration in Swedish Distressed Neighbourhoods: Can Area-based Urban Policies Counteract Segregation Processes?, Housing Studies 19 (4) pp. 517-539.

Bailey, N. \& Livingston, M. (2007) Population Turnover and Area Deprivation, Bristol: Joseph Rowntree Foundations.

Bergström, L. (forthcoming) The Impact of Residential Mobility on Measurements of Neighbourhood Effects, Housing Studies.

Bergström, L., van Ham, M. \& Manley, D. (2010) Neighbourhood reproduction through neighbourhood choice, Paper presented at meeting of the European Network for Housing Research, Istanbul, Turkey, July 2010.

Bolt, G. \& van Kempen, R. (2003) Escaping Poverty Neighbourhoods in the Netherlands, Housing, Theory and Society 20 pp. 209-222. 
Bowes, A., Dar, N. \& Sim, D. (1997) Tenure preference and housing strategy: An exploration of Pakistani experiences, Housing Studies 12 pp. 63-84.

Bråmå, Å. (2006) "White flight”? The production and reproduction of immigrant concentration areas in Swedish cities, 1990-2000, Urban Studies 43 (7) pp. 1127-1146.

Brooks-Gunn, J. Duncan, G. \& Aber, J. (Eds) (1997), Neighborhood Poverty: Vol. 1 Context and Consequences for Children, New York: Russell Sage Foundation

Brown, L. A. \& Moore, E. G. (1970) The Intra-Urban Migration Process: A Perspective, Geografiska Annaler B 52 (1) pp. 1-13.

Burrows, R. \& Rhodes, D. (2000) The geography of misery: area disadvantage and patterns of neighbourhood dissatisfaction in England, in: J. Bradshaw \& R. Sainsbury (Eds), Researching Poverty, Aldershot: Ashgate.

Clark, W.A.V. (1991) Residential Preferences and Neighborhood Racial Segregation: A Test of the Schelling Segregation Model, Demography 28 pp. 1-19.

Clark, W.A.V. (1992) Residential Preferences and Residential Choices in a Multiethnic Context, Demography 29 pp. 451-466.

Clark, W.A.V., Deurloo, M. \& Dieleman, F. (2006) Residential Mobility and Neighbourhood Outcomes, Housing Studies 21 (3) pp. 232-342.

Clark, W.A.V. \& Ledwith, V. (2006) Mobility, housing stress and neighbourhood contexts: evidence from Los Angeles, Environment and Planning A 38 pp. 1077-1093.

Crowder, K. (2000) The Racial Context of White Mobility: An Individual-Level Assessment of the White Flight Hypothesis, Social Science Research 29 pp. 223-257.

Dawkins, C. J., Shen, Q. \& Sanchez, T. W. (2005) Race, space, and unemployment duration, Journal of Urban Economics 58 pp. 91-113.

Duncan, G., Connell, J. \& Klebanov, P. (1997) Conceptual and methodological issues in estimating causal effects of neighborhoods and family conditions on individual development, in: J. Brooks-Gunn, G. Duncan \& J. Aber (Eds) Neighborhood Poverty: Vol. 1 Context and Consequences for Children, New York: Russell Sage Foundation.

Ellen, I. (2000) Sharing America's Neighborhoods, Cambridge: Harvard University Press.

Emerson, M. O., Yancey, G. \& Chai, K. J. (2001) Does Race Matter in Residential Segregation? Exploring the Preferences of White Americans, American Sociological Review 66, pp. 922-935.

Feijten, P. \& van Ham, M. (2009) Neighbourhood change ... reason to leave?, Urban Studies 46 (10) pp. 2103-2122.

Finney, N. \& Simpson, L. (2009) Population Dynamics: The Roles of Natural Change and Migration in Producing the Ethnic Mosaic, Journal of Ethnic and Migration Studies 35 (9) pp.1479-1496.

Galster, G. (1987) Homeowners and neighborhood reinvestment, Durham, NC: Duke University Press.

Galster, G. (2008) Quantifying the Effect of Neighbourhood on Individuals. Challenges, Alternative Approaches and Promising Directions, Journal of Applied Social Sciences. Schmollers Jahrbuch 128 (1) pp.7-48.

Galster, G., Andersson, R., Musterd, S. \& Kauppinen, T. M. (2008) Does neighborhood income mix affect earnings of adults? New evidence from Sweden, Journal of Urban Economics 63 pp. 858-870. 
Galster, G., Marcotte, D. E., Mandell, M., Wolman, H. \& Augustine, N. (2007) The Influence of Neighborhood Poverty During Childhood on Fertility, Education, and Earnings Outcomes, Housing Studies 22 (5) pp. 723-751.

Galster, G. (2011) The Mechanism(s) of Neighbourhood Effects: Theory, Evidence, and Policy Implications. In van Ham M., Manley D., Bailey N., Simpson L., Maclennan D. (eds) Neighbourhood Effects Research: New Perspectives. Chapter 2. Springer Dordrecht.

Guest, A. M., Cover, J. K., Matsueda, R. L. \& Kubrin, C. E. (2006) Neighbourhood context and neighbouring ties, City and Community 5 pp. 363-385.

Harris, D. R. (1999), Property Values Drop When Blacks Move In, Because...”: Racial and Socioeconomic Determinants of Neighborhood Desirability, American Sociological Review 64, pp.461-479.

Heckman, J. (1979) Sample selection bias as a specification error, Econometrica 47 pp.153-161

Hoffman, S. D. \& Duncan, G. J. (1988) Multinomial and Conditional Logit DiscreteChoice Models in Demography, Demography 25 (3) pp. 415-427.

Ioannides, Y. M. \& Zabel, J. E. (2008) Interactions, neighbourhood selection and housing demand, Journal of Urban Economics 63 pp. 229-252.

Jencks, C. \& Mayer, S. (1990) The social consequences of growing up in a poor neighborhood, in: L. Lynn \& M. McGeary (Eds) Inner-city Poverty in the United States, Washington: National Academy Press.

Kearns, A. \& Parkes, A. (2003) Living in and leaving poor neighbourhoods in England, Housing Studies 18 (6) pp. 827-851.

Lee, B. A., Oropresa, R. S. \& Kanan, J. W. (1994) Neighborhood Context and Residential Mobility, Demography 31 (2) pp. 249-270.

McFadden, D. (1974) Conditional logit analysis of qualitative choice behaviour, in: P. Zarembka (Ed), Frontiers in econometrics, New York: Academic Press.

Molina, I. (1997) Stadens rasifiering. Etnisk boendesegregation i folkhemmet (Racialization of the City. Ethnic Residential Segregation in the Swedish Folkhem), Geografiska regionstudier $\mathrm{Nr}$ 32, Uppsala University.

Oreopoulos, P. (2003) The long-run consequences of living in a poor neighborhood, Quarterly Journal of Economics 118 pp. 1533-1575.

Parkes, A., Kearns, A., \& Atkinson, R. (2002) What Makes People Dissatisfied with their Neighbourhoods? Urban Studies 39 (13) pp. 2413-2438.

Permentier, M., van Ham, M. \& Bolt, G. (2009) Neighbourhood reputation and the intention to leave the neighbourhood, Environment and Planning A 41 (9) pp. $2162-2180$.

Portes, A., \& Manning, R. (1986) The immigrant enclave: Theory and empirical examples, in: S. Olzak \& J. Nagel (Eds) Competitive ethnic relations, New York: Academic Press.

Puhani, P. (2000) The Heckman Correction for sample selection and its critique, Journal of Economic Surveys 14 (1) pp. 53-68

Quillian, L. (2002) Why Is Black-White Residential Segregation So Persistent?: Evidence on Three Theories from Migration Data, Social Science Research 31 pp. 197-229.

Quillian, L. \& Bruch, E. (2010) Race and Class in Neighborhood Mobility: A Conditional Logit Model of Neighbourhood Migration, Paper presented at the meeting of the Population Association of America, Dallas, Texas, the United States, April 2010. 
Sampson, R. \& Sharkey, P. (2008) Neighborhood Selection and the Social Reproduction of Concentrated Racial Inequality, Demography 45 (1) pp. 1-29.

Schelling, T. (1969) Models of Segregation, The American Economic Review 59 (2) pp. 488-493.

Schelling, T. (1971) Dynamic Models of Segregation, Journal of Mathematical Society 1 pp. 143-186.

Skifter Andersen, H. (2003) Urban Sores: On the Interaction between Segregation, Urban Decay and Deprived Neighbourhoods, Aldershots: Ashgate.

Tienda, M. (1991) Poor People and Poor Places: Deciphering Neighborhood Effects on Poverty Outcomes, in: J. Huber (Ed), Macro-Micro Linkages in Sociology, Newbury Park, CA: Sage Publications.

Turner, M. A., Ross, S. L., Galster, G. C. \& Yinger, J. (2002) Discrimination in Metropolitan Housing Markets: National Results from Phase I HDS 2000, Washington: The Urban Institute.

van Ham, M. \& Clark, W. A. V (2009) Neighbourhood mobility in context: household moves and changing neighbourhoods in the Netherlands, Environment and Planning A 41 pp.1442-1459.

van Ham, M. \& Feijten, P. (2008) Who wants to leave the neighbourhood? The effect of being different from the neighbourhood population on wishes to move, Environment and Planning A 40 pp. 1151-1170.

van Ham, M. \& Manley, D. (2009) Social Housing Allocation, Choice and Neighbourhood Ethnic Mix in England. Journal of Housing and the Built Environment 24, 407-422.

van Ham, M. \& Manley, D. (2010) The effect of neighbourhood housing tenure mix on labour market outcomes: a longitudinal investigation of neighbourhood effects, Journal of Economic Geography 10 (2) pp.257-282.

van Ham, M. (forthcoming a) Housing Behaviour. In D. Clapham, W.A.V. Clark and K. Gibb (eds) Handbook of Housing Studies. Chapter, 4. Sage: London.

van Ham, M. (forthcoming b) The Economics of Housing Choice. In Smith S.J., Elsinga M., Fox-O’Mahony L, Ong S.E., Wachter S. (eds) The International Encyclopedia of Housing and Home. Entry 94. Elsevier: Oxford.

Zubrinsky, C. L. \& Bobo, L. (1996) Prismatic Metropolis: Race and Residential Segregation in the City of the Angels, Social Science Research 25, pp. 335-374. 